\title{
The Application of Aesthetic Education in Aerobics Teaching Research Yuan-Yuan LIN ${ }^{\mathrm{a}}$, Xiao-Feng HAN ${ }^{\mathrm{b}}$ \\ Institute of Rehabilitation, Gannan Medical University, Ganzhou341000, China \\ 9137897@qq.com
}

Keywords: Aerobics, Eons education, Application research on.

\begin{abstract}
Aerobics is the product of the development of The Times. In this paper, Using documentary and logical analysis, demonstrated the relationship between the aesthetic Aerobics and calisthenics teaching. Aerobics is loved by college students, In order to help students build good teaching atmosphere, consciously cultivate and improve students' sensibility to the taste and creativity, to make students master the basic technology and skills, aesthetic education in the teaching of the calisthenics should edify sentiment in the movement, optimize the quality, improve the efficiency of the physical education.
\end{abstract}

Aerobics is a sports program that combines music, dance, gymnastics and aesthetics. Aerobics Teaching is a complex cognitive system, it not only pays attention to students' body activities, but also pay attention to inner spirit, consciousness and form, the action of aesthetic education closely referred to as aesthetic education. Aerobic is to use artistic beauty, natural beauty and social life, cultivate students' aesthetic point of view, let them feel the beauty, appreciate beauty, and have the power to create beauty, beauty in sports, beauty in the sports can inspire people, education people. As a sports program, aerobic exercise not only emphasizes "health", but also emphasizes "beauty". Aerobics combines health, strength and beauty, and can edify the good sentiment. Aesthetic education is widely used in the teaching of aerobics, which will have a double effect on teaching.

\section{Body Language in Teaching}

Example is better than precept. Aerobics teaching is a kind of teaching through physical activity. There in lies the content of the teaching.PE teacher is a direct follower of education. Body language is the body language or sign language, which belongs to the non-verbal information and makes sports education "language" factor. Posture language beauty is the human body posture or attitude of a good expression, it reflects the people's thoughts and feelings, grade of knowledge, moral accomplishment, wisdom, personality, etc. This kind of beauty is people's essential strength directly or shows ideal image, and it is closely related to people's mental quality.

\section{The Form of Body Language}

The expressions of body language beauty mainly include facial expression, behavior, body expression, body appearance, movement expression, etc. Through the judgment, appreciation and perception of these images, people experience the aesthetic pleasure and enjoyment, which is the aesthetic feeling of body language.PE teachers show this beauty in aerobics teaching, this beauty not only make students get beautiful feeling and mellow, not only help students to set up the correct body language aesthetic idea and aesthetic standard, but also stimulate students to shape on pursuing the graceful posture language and power. Therefore, the essence of posture language beauty and body image, mainly passenger transportation between physique, graceful posture, elegant manners, generous appearance agile, skilled, harmonious demonstration operation. From the perspective of ethical connotation, the body language expresses truth and goodness, which reflects the moral sentiment, cultural taste, firm character, open-minded mind and strong will quality of positive spiritual quality.

\section{The Striking Feature of Body Language Beauty}

Solemn and steady manner, graceful bearing, handsome body friendly expression, expressive eyes 
are the concrete manifestation of The striking feature of body language beauty. Human body language beauty education and influence have social value, its broad influence and lasting appeal have been affirmed by the world. Prehistoric children can get sports education from their parents, such as the boy imitated his father javelin throwing stones hunting or resist foreign invasion, "the father teach son mode of education", is the most basic accept physical education in the early years of the human. By means of imitation, the children learn the basic skills of knowledge from their parents. The most important thing is that they get emotion, will quality, moral accomplishment and the influence of cultural customs and infection, including the influence of posture language beauty form their parents It can be seen that education has a long history, and it is closely related to sports, and it is closely related to the fitness exercise program which is now popular around the world.

\section{The Application of Body Language Beauty in Aerobics Teaching}

Every move, pose demonstrated by sports teacher's, will lurking certain demonstration role in education and aesthetic significance in the process of calisthenics teaching. Elegant manner and graceful posture image in aerobics teaching always an example for students to follow and respect, especially teachers, and it is can arouse students body art show more beautiful pursuit in art. Although body language image has certain artistic charm and appeal, but we should admit that express the natural, beautiful and harmonious, reflects a kind of healthy, positive, real spirit to strive for the novelty. The pursuit of sensory stimulation, lack of self-restraint body art show, should fundamentally stop and put an end. So, improve teachers' body language of artistic expression can broaden the artistic beauty of the creation of aerobics. Form bright individuality and the perfect image, to the students to influence of body and mind, the more stimulates the student to the pursuit of beauty, appreciation and shaping desires, the more students will get moral, intellectual, physical, will eventually make all-round development.

\section{Beauty of Language in Teaching}

Language is group teaching in physical education teaching, imparting the basic knowledge, it can training students' ability, to improve students' quality is one of the important means of concise, lively, rigorous, profound, has the stimulation and infectious form of language, the scientific design, clever apply, to create a lively, pleasant and harmonious classroom atmosphere, interfere with the students actively participate in various sports activities, form the unique teaching style, to efficiently complete the teaching mission, improve the students' aerobics culture, has a very important role.

\section{Appreciation Language}

The appreciation language should be the main melody in the whole teaching process. American education scientists have said that "the most essential characteristic of human nature is the desire to be appreciated by others". In the aerobics teaching. If satisfying the students' psychological needs, students can have a pleasant psychological experience, students can better play their own strengths and show their advantages.

\section{Teacher's Language Should be Emotional}

Students have emotional needs, and they need respect, warmth, friendship and instruction from teachers. Teachers' language according to different purposes, or serious, moderate, or up, no matter what kind of voice, have incentive to students, should let the students feel the teacher for his care. For students who have had sports injuries, after meeting, gently ask, "did you fully recover from your injury?" It will make them feel warm to the students who have made mistakes in the exercise, and say, "the body is falling, but the belief of victory is not defeated." Believe that you don't have to say anything more, he will certainly cheer up and keep practicing.

\section{"Do in Rome as Rome does"}

Teachers should be classified according to different types of aerobics. Teachers should design 
different languages according to different project classification, different teaching period. For example, in the teaching of mass aerobics, to the students, "music is the voice from nature, with the joyful sound, jump with me!” It must be more attractive than the opening remarks of "we have a mass fitness class today”.

\section{"Password" and "Slogan"}

The wide application of "password" and "slogan" is the aerobics language form in the teaching of aerobics. Clear, bright, passionate, full of spirit, spirit, god's password and slogans, such as "Come on!", " Go"! Wait, can make the student the mood is cheerful, the spirit is fresh, the spirit is bright, can make the whole teaching process appears lively, the interest is full!

\section{Language Characteristic}

The teaching of aerobics, concise, concise, accurate is its biggest language characteristic. Intensive practice is the main theme of the classroom teaching and the scientific and accurate and reasonable application of the language, to the whole class to make the finishing point. In aerobics teaching language is the main medium for the spread of knowledge, the bridge through the relationship between teachers and students. Teachers can guide students to master the main approaches of setting-up exercise knowledge, technology and skills. The teaching language specification should be correct, vivid, especially hence in the interpretation of the behavioral essentials sure can put the calisthenics teaching lively, relaxed and happy, can attract and infect students actively to learn all kinds of setting-up exercise knowledge and skills, can make the student's body and mind obtain the comprehensive development.

\section{Beautiful Teaching Atmosphere}

Pay attention to creating a beautiful teaching atmosphere in aerobics teaching. Students have strong competitive spirit, want to leave a good impression to the teachers and students, thus to motivate students to perform, together to create a good classroom atmosphere, in this way, students will gradually formed in the osmosis of discipline, deeply loves the collective virtue.

\section{Reasonable Arrangement of Teaching}

In order to create good teaching atmosphere, we must according to the ease of calisthenics teaching material, the size of the amount of exercise, exercise density of the whole teaching process in place and then according to the demand of the teaching purpose, or in front of the teaching material is difficult by several levels of "steps" enable students to "ascend" smoothly, to the expected teaching purpose, or in a more bitter rigorous teaching have to arrange some enjoyable and interesting for the following teaching activities, such as small singing and dancing, games, etc., make the whole class presents a strong with the weak compact, lively, cheerful anacreontic, teaching, make students in the cheerful atmosphere of the uninterrupted acquired knowledge, exercise the body, also won a psychological satisfaction at the same time, increased the interest in learning.

\section{Pay Attention to Creating a Site in the Layout}

Beautiful site layout can improve students' interest in learning and beautify their feelings. For example, gymnastics room neat ,bright mirror, clean wood floors, the reasonable layout of the equipment used, can bring aesthetic feeling of pleasing to students ,Beautiful site layout can produce pleasant psychological experience, and it is also can inspire the enthusiasm of them practice.

\section{Conclusion}

Aerobics is the product of the development of The Times, and it is of great importance to exercise the value of aerobic exercise in people's pursuit of health. Healthy mind and healthy body is closely related, beauty can promote the psychological balance. The physical and mental health on 
calisthenics teaching with aesthetic education principle, carefully infiltration of aesthetic education in practice lesson, not only can teenagers body symmetry, not only can posture to develop in the direction of fit, but also can make the students on the spirit of enlightenment. Beauty is everywhere, so is the calisthenics teaching. How to study in calisthenics teaching beauty? How to find beauty and create beauty? How to make the small and medium-sized accept virtue edification of the students' emotion mental state tend to be noble, truly become the morality, intelligence and physique, fatigue all-round development of useful talents, is an important subject for the colleagues of the calisthenics in China to further explore.

\section{Reference}

[1]ZHU Min,Infiltration Path of Aesthetic in College Aerobics Teaching, $<$ Sport Science and Techno logy>,2015,(4)P 164-165,(In Chinese)

[2]ZhangGuoqing, Yang Wei,The Research and Practice of Inquiry-style Teaching in Aerobics Cours e in PE Department of Colleges and Universities, <Bulletin of Sport Science \& Technology>2017,(1 )P17-18,(In Chinese)

[3]ZHANG Bao - jin,Research on the Application of Micro Teaching in the Aerobics Teaching in Higher Vocational Colleges, <Journal of Guangzhou Physical Education Institute>, 2017(3) P108-113,(In Chinese)

[4]WANG Ke,GUO Jian-hua,Teaching Reform of Aerobic Course in Colleges and Universities, $<$ Jo urnal of Jishou University(Natural Science Edition)> 2013(6)p93-96,(In Chinese)

[5]YANG Min, REN Chun- xiang, CHEN Xi- na ,Innovation of aerobics teaching mode in colleges and universities, <Shandong Sports Science \& Technology>, 2016(1)P 71-74,(In Chinese)

[6]XU Li, HE Zong-hong ,Research on the Application of Aerobics Club Teaching Model in Physic al Education Curriculum in Higher Vocational Colleges, $<$ Journal of Shaoguan University(Social Sci ence Edition)>2017(8)P 85-88,(In Chinese)

[7]CHEN Xiao - Rui ,Problems and Countermeasures in Aerobics Teaching in Colleges, $<$ Journal of Daxian Teachers College>,2010(2)P122-124,(In Chinese) 